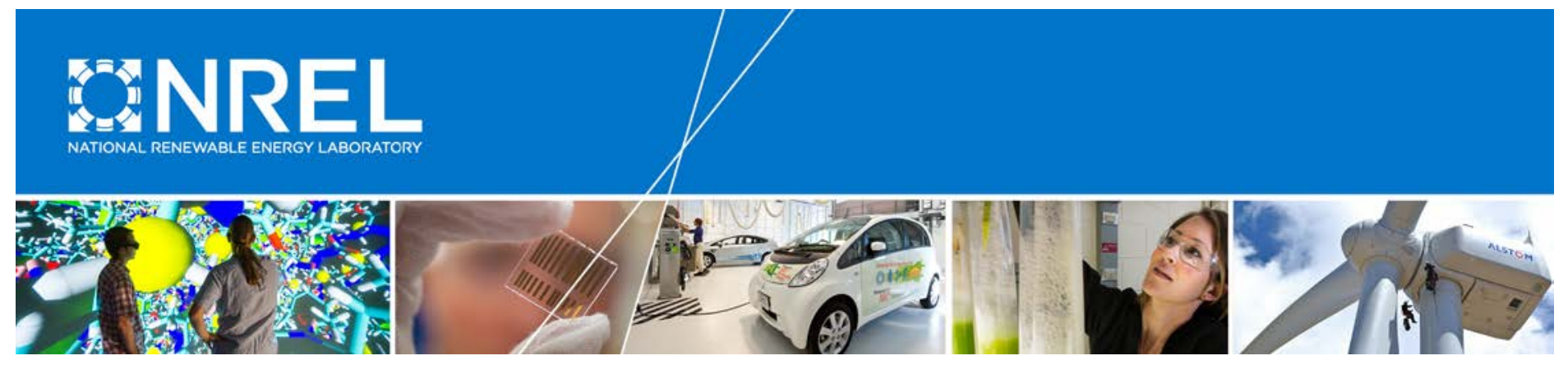

\title{
Automated Vehicle Policy and Regulation: A State Perspective Workshop
}

\section{Summary}

Edited by Stanley E. Young and Aaron Levine National Renewable Energy Laboratory

NREL is a national laboratory of the U.S. Department of Energy Office of Energy Efficiency \& Renewable Energy Operated by the Alliance for Sustainable Energy, LLC

This report is available at no cost from the National Renewable Energy Laboratory (NREL) at www.nrel.gov/publications.

Technical Report

NREL/TP-5400-66576

June 2016 


\section{Automated Vehicle Policy and Regulation: A State Perspective Workshop}

\section{Summary}

Edited by Stanley E. Young and Aaron Levine National Renewable Energy Laboratory

Prepared under Task No. 0654.1502

NREL is a national laboratory of the U.S. Department of Energy Office of Energy Efficiency \& Renewable Energy Operated by the Alliance for Sustainable Energy, LLC

This report is available at no cost from the National Renewable Energy Laboratory (NREL) at www.nrel.gov/publications.

National Renewable Energy Laboratory 15013 Denver West Parkway Golden, CO 80401

303-275-3000 • www.nrel.gov

\section{Technical Report}

NREL/TP-5400-66576

June 2016

Contract No. DE-AC36-08G028308 


\section{NOTICE}

This report was prepared as an account of work sponsored by an agency of the United States government. Neither the United States government nor any agency thereof, nor any of their employees, makes any warranty, express or implied, or assumes any legal liability or responsibility for the accuracy, completeness, or usefulness of any information, apparatus, product, or process disclosed, or represents that its use would not infringe privately owned rights. Reference herein to any specific commercial product, process, or service by trade name, trademark, manufacturer, or otherwise does not necessarily constitute or imply its endorsement, recommendation, or favoring by the United States government or any agency thereof. The views and opinions of authors expressed herein do not necessarily state or reflect those of the United States government or any agency thereof.

This report is available at no cost from the National Renewable Energy Laboratory (NREL) at www.nrel.gov/publications.

Available electronically at SciTech Connect http:/www.osti.gov/scitech

Available for a processing fee to U.S. Department of Energy and its contractors, in paper, from:

U.S. Department of Energy

Office of Scientific and Technical Information

P.O. Box 62

Oak Ridge, TN 37831-0062

OSTI http://www.osti.gov

Phone: 865.576.8401

Fax: 865.576.5728

Email: reports@osti.gov

Available for sale to the public, in paper, from:

U.S. Department of Commerce

National Technical Information Service

5301 Shawnee Road

Alexandria, VA 22312

NTIS http://www.ntis.gov

Phone: 800.553 .6847 or 703.605 .6000

Fax: 703.605.6900

Email: orders@ntis.gov 


\section{Executive Summary}

A workshop held on May 18, 2016, at the University of Maryland focused on key principles that should govern state policy decisions intended to ensure the safe operation of automated vehicles (AVs). The patchwork approach taken by early state adopters had primarily addressed only testing of these vehicles. As uncertainties in technology and business models play out, and in the absence of more suitable policies and regulations, states are relying on laws created for conventional vehicles to govern AV operation. The workshop addressed these challenges with three panel discussions that examined the underpinnings of policy development, factors affecting policy decisions, and the ultimate impact of AVs in a number of areas, including economic competitiveness; quality of mobility, particularly for the disabled community; and energy use and emissions.

The workshop was co-hosted by the University of Maryland's National Transportation Center, the University of Maryland Center for Advanced Transportation Technology, the I-95 Corridor Coalition, and the National Renewable Energy Laboratory. Driverless Transportation served as the media sponsor. Presentations from the workshop are available at https://app.box.com/v/AVStatePolicyWorkshop.

Two panel sessions featured nationally known speakers who addressed a variety of topics, including legal, insurance, social equity, and data privacy issues. The panels sought to identify key principles that can provide a common foundation for the operation and regulation of AVs across all states. This is critical to ensure safe operation, efficient travel, and environmental benefits when AVs become commercially available, as well as to speed the deployment of future advances in this technology. In a third session, a panel of elected officials provided jurisdictional-specific viewpoints. This group is often tasked with managing expectations and fears of the general public, as state legislatures wrestle with the considerations of the potential benefits of this new technology and the prudent policies needed to safeguard constituents. 


\section{Table of Contents}

Executive Summary iii

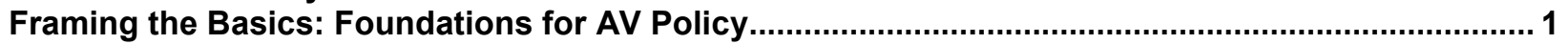

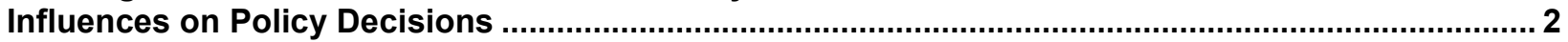

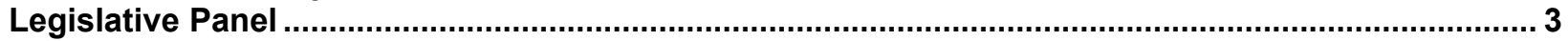

AVs from an Energy Perspective: Potential for Positive and Negative Impacts ............................... 4

Conclusion: Public Perceptions and Considerable Promise ............................................................... 4 


\section{Framing the Basics: Foundations for AV Policy}

The first panel session, Framing the Basics, moderated by Dr. Stanley Young of the National Renewable Energy Laboratory, examined foundational issues associated with state policy and regulation.

The first panelist, Bryant Walker Smith from the University of South Carolina, recommended precursor activities to states in approaching policy development. Historically, policy and regulation have been developed primarily in reaction to new technology, using the closest technical analogy to govern initial rollout until proven inadequate. Mr. Smith suggested that states could prepare by performing audits of existing laws to understand how they might address automated vehicles (AVs) and to identify where action is required. Educating government agencies, constituents, stakeholders, and industry and communicating realistic expectations could be approached either by a special task force or a government office. Lastly, Mr. Smith recommended states name a point person to coordinate AV efforts with the federal government, state administrative agencies, the state legislature, local regulators, and the public. Further recommendations from Mr. Smith are detailed in How Governments Can Promote Automated Driving, which is now available at https://newlypossible.org/wiki/index.php?title=Publications.

Robert Peterson, professor of law from Santa Clara University, discussed the state of California's recently released draft regulations in a presentation entitled A Look at California's Attempt at Automated Vehicle Regulation - The Good, The Bad, and The Ugly. Professor Peterson shared examples of how poorly defined terms resulted in regulations that actually discouraged, rather than promoted, automated driving. For example, current automotive technology has already made the proposed definition for an AV obsolete. Dr. Peterson emphasized the need to approach regulation at a pace that allows technology to mature without presenting undue legal hurdles.

Frank Douma, state and local policy program director from the Humphrey School of Public Affairs at the University of Minnesota, shared information on a Minnesota AV legislative initiative for people with disabilities. What started as a data gathering exercise among Minnesota's disabled community quickly grew into an advocacy group to promote AV adoption. The group insisted that AVs must provide equitable mobility options, citing legal precedence with the Olmstead plan, a broad series of key activities Minnesota must accomplish to ensure people with disabilities are living, learning, working, and enjoying life in the most integrated setting. The enthusiasm and focus of the effort have put Minnesota at the forefront of AV advocacy. A significant number of Minnesotans with disabilities live in rural areas, and there is rapid growth of the elderly population, making this effort a strong example for states with similar demographics.

Discussion among panelists and audience members explored a number of topics related to nearterm state regulation. Participants emphasized the need for flexibility of approach, not only when crafting future legislation, but also when considering AV issues currently under debate. States have traditionally regulated driving behavior through the issuance of motor vehicle licenses and enforcement of traffic laws, and the federal government has regulated vehicle safety, but those roles are beginning to blur as driving is controlled more by machine hardware and software than by the driver. That has led to calls for a stronger federal role in legislation to harmonize AV operation across all 50 states. In response, the National Highway Traffic Safety Administration 
(NHTSA) plans to issues guidelines (but not regulations) for state AV policy later in 2016. Highlights from comments to NHTSA's proposed "Operational Guidelines for Autonomous Vehicles" can be found here. The expansion of NHTSA's authority is anticipated to be a point of debate moving forward. Timing and state-versus-federal regulation of equity issues, such as equal access for the disabled, were also discussed.

\section{Influences on Policy Decisions}

The second panel concentrated on factors that influence policy decisions and was moderated by Richard Bishop of Bishop Consulting.

Dorothy Glancy, professor of law from Santa Clara University, shared perspectives of AV data privacy from her extensive work in the areas of data privacy and transportation law. The expectation of privacy in private automobiles is well established, requiring law enforcement to have probable cause before a vehicle is searched. These precedents are anticipated to carry over to AVs, including access to the large quantities of data created by AVs. Unlike in other countries, "data ownership" is not an established principle in the United States. Rather, privacy protection and access to data relative to privacy concerns receive treatment in law. As vehicles become increasingly digital, it will be a challenge to protect individual privacy. In addition to privacy concerns, securing AVs against hackers and terrorist threats is becoming an escalating implementation issue.

James Anderson of Rand Corporation addressed the workshop with a talk entitled 50 Separate Approaches, or One Unified Approach, extending the state-versus-federal jurisdictional debate. Mr. Anderson introduced the topic from the benefits perspective that is likely to guide regulation as well as pace of adoption, looking at the advantages and disadvantages of AVs. If the current pattern of insurance and driver licensing is carried into the world of AVs, rapid AV adoption is likely to stress the prevailing systems. This is particularly true in the case of insurance, where reliance on extensive field data can result in pricing and regulation changes taking longer than a decade. Current NHTSA initiatives and industry lobbying for a central unified approach to AV certification and policy would challenge states' rights to self-regulate, but also would be a much more efficient path to enabling widespread AV deployment. However, given states' entrenched processes and the affront to states' rights, a larger federal role seems equally unlikely. NHTSA's guidelines for state policy are perhaps a compromise to balance competing concerns.

Kelsey Brunette, ideation analyst for Munich Reinsurance America, Inc., shared the insurers' perspective. Kelsey stressed that the well-established insurance practices distinct to each state may present larger impediments to rapid evolution of AVs than some of the technology challenges. Although the insurance industry will adapt and evolve, justification to state regulators has typically required several years of field data such that change cycles are typically a decade long. The conservative insurance industry is actively promoting AV safety technology, while also recognizing the enormous impact that reduced crashes will have on the "crash economy" ecosystem. Ms. Brunette displayed a long list of industry players who derive significant revenue from the prevailing "crash economy." Lastly, whether liability is held by private automobile insurers or original equipment manufacturers, insurance companies will continue to play a key role in pooled risk and be a primary consideration in the formulation of AV policy. 
Further panel discussion took place with respect to evolving business models. As AVs increase original equipment manufacturers' liability for accidents, insurance and licensing that were originally human-driver centric will evolve to accommodate the digital driver. Black box recorders standard on commercial aircraft are expected to become common in automobiles, taking much of the uncertainty out of fault evaluation. A question brought up the possible impact that mobility-as-a-service providers might have in reducing private automobile ownership and precipitating a shift to fleet ownership. Panel members acknowledged that most projections are based on the assumption that private vehicle ownership will continue to dominate the market, and that if mobility-as-a-service dramatically alters this paradigm, the potential exists for significantly different policy and regulation basis.

\section{Legislative Panel}

The legislative panel was moderated by Burney Simpson, editor of Driverless Transportation, and featured four elected officials from surrounding states and the District of Columbia. Panelists provided a short history of AV policy and regulation efforts within each of their jurisdictions, as well as the motivations behind the initiatives.

Mary M. Cheh has served on the Council of the District of Columbia since 2007 and is currently the chairperson of the Committee on Transportation and the Environment. Ms. Cheh shared DC's enabling legislative measures for the establishment of robotized package delivery, as well as its AV testing law, one of the first in the nation. DC's highly developed urban infrastructure provides an opportunity and a challenge to those seeking to implement new mobility tools.

Delegate Glenn R. Davis represents the $84^{\text {th }}$ House District in the Virginia General Assembly, serving on the Education and Transportation Committees. Virginia, similar to California and Michigan, strives to be on the forefront of automotive technology and research. Led primarily by Virginia Tech at Blacksburg, legislation has enabled AV research and testing within specified corridors, allowing the state to compete for corporate and industry research funds, as well as to prepare for future general adoption of AVs.

Delegate David Fraser-Hidalgo represents the $15^{\text {th }}$ District in the Maryland House of Delegates. He serves on the Environmental and Transportation Committees, as well as the Motor Vehicle and Transportation Subcommittee, and his major focus areas include the environment, renewable energy, and electric cars. Maryland has attempted unsuccessfully to pass AV legislation for two years. A Department of Motor Vehicles-led task force comprised of state agencies has been formed to address, educate, and communicate the anticipated impact of AVs on the state mobility system.

Tennessee State Senator Mark Green has served Senate District 22 since 2013. The Tennessee economy is bolstered by automobile manufacturing, with Nissan North America headquarters and major VW and General Motors plants. AV legislation in Tennessee ensures that a supportive policy environment for the auto industry will continue and begin to attract research and design organizations, as well as manufacturing companies. According to Senator Green, as a result of recent legislation, Tennessee currently ranks third nationwide in the list of AV-friendly states.

Lively and varied discussion emphasized that the policy and legislation diverged between jurisdictions represented by the panelists based on political factors. Common to all the panelists 
was fear among constituents, especially older voters, about AV safety, as well as the technology's potential for eliminating jobs. Even so, the panel was in agreement that the safety, productivity, and quality of life benefits of AV technology far outweigh possible risks, and that changes are coming whether or not the states are prepared. The panelists also acknowledged that investments in technology needed to be balanced against those in infrastructure. If AV technology could increase vehicle throughput efficiency, a relatively small investment in technology may allow a state to forego a sizeable investment in building a new roadway or widening an existing roadway. States need to guard against waste with any new road investments, whether traditional steel and concrete or technology to support AVs. The waste risk for technology is premature obsolescence and non-operability with adjoining states. The question of how to pay for AV-related infrastructure was also discussed, with general consensus that some type of consumption fee (such as mileage-based fees) should be implemented to pay for road improvements rather than imposing a new tax.

\section{AVs from an Energy Perspective: Potential for Positive and Negative Impacts}

Aaron Levine, a National Renewable Energy Laboratory legal and regulatory analyst, presented Automated Vehicles from an Energy Perspective. Mr. Levine shared results of early research showing the potential of AVs to significantly alter future energy use and greenhouse gas (GHG) production depending on the method of adoption. One scenario indicated large potential increases in energy consumption, congestion, and GHG emissions due to induced demand and related growth in vehicle miles traveled, while a set of more optimistic projections showed significant potential for decreased petroleum use and GHG emissions with significantly increased adoption of electric vehicles as part of the AV fleet. The presentation stressed that energy policy and AV policy could be approached in tandem as climate change looms large in national and international priorities.

\section{Conclusion: Public Perceptions and Considerable Promise}

Alain L. Kornhauser, professor and director of the Transportation Research Program at Princeton University, wrapped up the workshop with closing thoughts that AVs have a public perception problem rooted in industry semantics. The phrase "self-driving vehicles" suggests that individuals will continue to own cars and receive a variety of benefits from automation and connectivity. The term "driverless vehicles" suggests that the public mobility needs will be fully met by automated fleets with no need for vehicle ownership. Automated collision avoidance and lane keeping (ACA\&LK) offer fundamental safety improvements and are near-term capabilities for most auto manufacturers with several vehicles on the market already having optional ACA\&LK features. These terms and the fundamental concepts behind each are frequently mixed and confused in public discussion.

Self-driving vehicles can substantially increase vehicle miles traveled (and with it congestion, fuel use, and GHG emissions) because they make driving easier. In contrast, the driverless vehicle's ability to reposition itself without a human inside has the potential to fundamentally change the surface transportation system. Driverless vehicles present a viable path to increase 
passenger occupancy, gain fleet efficiencies, speed up adoption of electrified vehicles, and reduce or eliminate congestion. Driverless vehicles promise inexpensive, on-demand mobility for all, allowing personal miles traveled to increase while reducing or maintaining overall vehicle miles traveled, energy consumption, emissions, and congestion.

Dr. Kornhauser and other speakers throughout the day commented that society should endeavor to level the playing field for all transportation in terms of safety and sustainability, not only for $\mathrm{AVs}$, but also for conventional vehicles. If state policy is crafted to raise the bar for safety of $\mathrm{AVs}$, should it also raise the bar for conventional vehicles or require that conventional vehicles adopt key ACA\&LK technologies? If forward collision avoidance technology reduces crashes by $40 \%$, should jurisdictions mandate it for all new vehicles? If investments in infrastructure such as communications, signing, or better signal visibility are needed to enable AVs, these improvements should also benefit the drivers of conventional vehicles.

Lastly, driverless vehicles present a viable path to increasing mobility in a sustainable way through a combination of fleet efficiency, increased vehicle occupancy, and acceleration of electrified vehicle adoption. In such a scenario, personal miles traveled can continue to increase without detrimental effects. If the average vehicle occupancy is defined as the ratio of person mobility miles delivered to vehicle miles driven, then the average vehicle occupancy for today's vehicle is likely at or below one, accounting for the number trips in which a driver is present only to reposition the vehicle (such as returning it home, or picking up the next rider). If driverless vehicles can substantially increase average vehicle occupancy to close to two overall and to more than three during peak periods, driverless vehicles would approximately halve energy use and GHG emissions and eliminate most congestion, while providing safer on-demand mobility for all. 